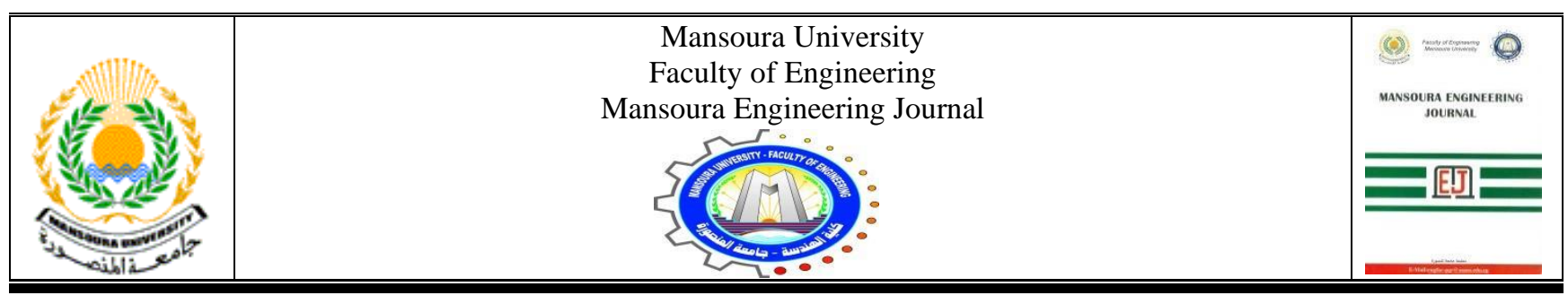

\title{
Mitigation of Transient Recovery Voltages using the Supercapacitor
}

\author{
Eman Awad and Ebrahim A. Badran
}

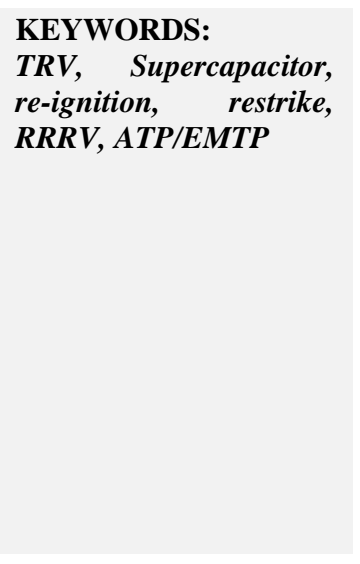

\begin{abstract}
This paper investigates the use of supercapacitor to mitigate the transient recovery voltage (TRV) in a simple power system. The TRV concept and the phenomena surround its occurrence such as re-ignition and restrike are represented. Also, the different waveshapes of TRV are evaluated. The effect of energizing different power system parameters, such as resistance and capacitance, resulting in TRV is evaluated. At first, the effect of energizing three different values of a damping resistance, one by one, is studied. Then, the influences of energizing of a capacitor, with three different values, on the tested system are illustrated. Finally, the effect of combining different values of the damping resistance and the capacitance are evaluated. The effect of using supercapacitor as TRV mitigation method is studied. Alternating transient program (ATP/EMTP) is used to simulate the test system and the proposed supercapacitor-based method. The simulation results ensure the validity of the proposed method.
\end{abstract}

\section{INTRODUCTION}

$\mathrm{S}$ UPERCAPACITORS have higher power density, faster dynamic response, and longer cycle life comparing with other energy storage devices such as batteries. Therefore, the applications in which the supercapacitor is used expanded to include wireless sensor networks, biomedical devices, electric and hybrid vehicles, and smart grid [1-3].

When a switching action occurs on a system, a substantial short circuit current usually flows. Therefore, the switching device starts to open; the parting of the circuit breaker contacts does not in itself interrupt the current. An arc will established between the parting contacts, through which the current will continue to flow. The arc across the contacts will continue until the current approaches zero. At current zero the arc will distinguish and the Transient Recovery Voltage (TRV) will appear across the open contacts. TRV is the voltage appearing 2020)

Received: (20 June, 2020) - Revised: (18 July, 2020) - Accepted: (25 July,

Corresponding Author: Eman Awad, Mansoura university, Faculty of Engineering, Electrical Engineering Department. (E-mail: eman_sk2008@yahoo.com). across the contacts of circuit breaker following current zero when a switching action occurs $[4,5]$.

When a capacitor is energized, TRV can be as high as $2 \mathrm{pu}$ at the capacitor location. The magnitude of TRV can be reduced by adding a damping resistance to the system [6-8].

Alternating transient program (ATP) is usually used to compute the TRV waveforms and to calculate its parameters. ATP is a computer program that allows an electrical system to be modeled and analyzed in the time domain, referred to as the electromagnetic transients program (EMTP). The program solves the system equations numerically in the time domain and the values of the TRV are determined for specific time instants within a user-specified simulation time $[9,10]$.

This paper investigates the use of supercapacitor to mitigate the TRV in a simple power system. The TRV concept and the phenomena surround its occurrence such as re-ignition and restrike are represented. Also, the different waveshapes of TRV are evaluated. The effect of energizing different power system

Ebrahim A. Badran, Mansoura university, Faculty of Engineering, Electrical Engineering Department. (E-mail: ebadran@hotmail.com). 
parameters, such as resistance and capacitance, resulting in TRV is evaluated. At first, the effect of energizing three different values of a damping resistance, one by one, is studied. Then, the influences of energizing of a capacitor, with three different values, on the tested system are illustrated. Finally, the effect of combining different values of the damping resistance and the capacitance are evaluated. The effect of using supercapacitor as TRV mitigation method is studied. ATP/EMTP is used to simulate the test system and the proposed supercapacitor-based method. The simulation results ensure the validity of the proposed method.

\section{TRANSIENT RECOVERY VOLTAGE}

\section{A. Transient Recovery Voltage Concepts}

The circuit breaker contacts movements have influence on TRV, as it caused the insulation gap stress and arcing in the interrupting medium [10,11]. Following current extinction, the interrupting media is trying to return from a conduction state to an insulator state $[12,13]$. But the attempting of the interrupting media to become a good insulator is incompatible with the increasing TRV $[13,14]$.

If the insulation recovers more quickly more than the TRV, after less than half cycle of power frequency, a successful interruption occurs, it is referred to as reigniting. Reigniting generally occurs almost immediately after the current zero, because the arc plasma containing conducting ions reestablishes current $[13,15]$.

However, if the interruption process is repeated more than one time. The interruption process continues until successful interruption occurs or until the breaker fails, it is designated a restrike [13].

Restrikes are really dielectric breakdowns and can occur anytime during the TRV cycle, although usually they are associated with breakdowns later in the cycle (say tens to hundreds of microseconds) when the TRV has sufficiently high magnitude. Such an event is akin to a lightning flash-over across an insulator [10, 16].

\section{B. Transient Recovery Voltage Waveshapes}

TRV have different waveshapes, the four categories given are listed based on increasing on rate of rise of recovery voltage (RRRV) [15].

\section{Exponential (over-damped) TRV Waveshape.}

The waveshape is obtained from a circuit breaker interrupts a switching action at its terminals in a well-developed substation which include step up and/or step-down transformers and a large number of transmission lines and/or underground cable $[13,15]$.

At higher short circuit currents which are associated with the transmission network, the TRV is less influenced by the natural power frequency. The RRRV, within the range of 0.5 to $3.5 \mathrm{kV} / \mu \mathrm{Sec}$, tends to decrease when the short circuit current increases $[15,17]$.

\section{Oscillatory (Under-damped) TRV Waveshape.}

The oscillatory TRV occurs generally when a switching action is limited by transformer or reactor and no transmission network is present to provide damping [17].

Even when a transmission network is presented it is possible for TRV to be oscillatory. When, the short circuit current is generally low ( $30 \%$ of rated short circuit current) due to the low number of transmission lines connected to the system. Also, to be oscillatory, the surge impedance of a source sideline has to be equal or higher than $0.5 \sqrt{ }\left(\mathrm{L}_{\text {eq }} / \mathrm{C}_{\text {eq }}\right)$ whereas; $\mathrm{L}_{\text {eq }}$, and $\mathrm{C}_{\text {eq }}$ are equivalent source inductance and capacitance, respectively [13, 17].

The frequencies associated with oscillatory TRV tend to be in the range of $1 \mathrm{kHz}$ to $100 \mathrm{kHz}$. The highest frequencies generally occur on the lowest voltage systems and the lowest frequencies on the highest voltage systems [15].

\section{Triangular (Sawtooth) TRV Waveshape.}

Sawtooth TRV is characterized by high RRRV. The RRRV of the triangular shape is mainly determined by the line surge impedance. The RRRV for this type of TRV is higher than exponential or oscillatory TRVs, however, the TRV peak is generally lower. These are seen more severe to circuit breakers because of high RRRV even though the peak of TRV is less $[13,17]$.

Even for any other type of TRV waveshapes, there is a small triangular characteristic at the beginning of the waveshape. This portion of the wave is referred to as the initial TRV and results from reflections on the bus work in the substation [15].

The closer the switching action is to the circuit breaker, the higher the RRRV of the initial TRV due to the higher short circuit current, while the crest magnitude of the triangular wave decrease due to the shorter time for the reflected wave to return [17].

\section{TRV EFFect ON A Simple PoWer System: Case Study}

The effect of various power system parameters on TRV at a simple power system is investigated using ATP. At first, ATP is used to simulate the switching action and the resulting in TRV is evaluated. The simulation results are compared with a published one [18, 19] for the same system data. Then, the effects of various power system parameters are discussed.

\section{A. Simulation of TRV Using ATP}

ATP is used to simulate a simple power system which consists of a voltage source, source impedance, vacuum circuit breaker, and a damping RC branch, which is added in parallel with the circuit breaker.

The tested power system and ATP model are illustrated in Fig. 1 (a) and (b), respectively. The parameters of the tested power system are given in Table 1 .

Fig. 2 shows a comparison between the published results in $[18,19]$ and ATP simulation results for the TRV which appears at the circuit breaker contacts after the current interruption. 


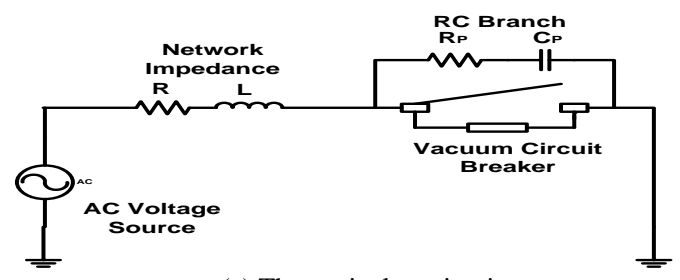

(a) The equivalent circuit

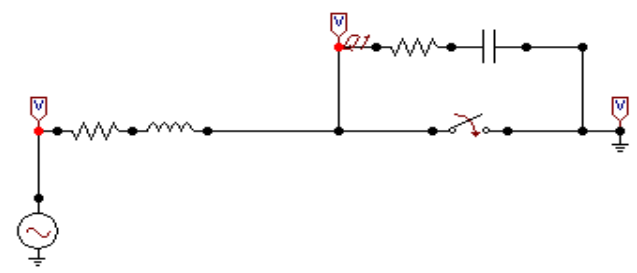

(b) ATP model

Fig. 1: The test power system.

Table 1

The Tested Power System Model Data [21].

\begin{tabular}{l||l}
\multicolumn{1}{c||}{ Parameter } & \multicolumn{1}{c}{ Value } \\
\hline Equivalent network resistance (R) & $0.1 \Omega$ \\
\hline Equivalent network inductance (L) & $2 \mathrm{mH}$ \\
\hline Resistance of RC branch (RP) & $200 \Omega$ \\
\hline Capacitance of RC branch (CP) & $85 \mathrm{nF}$ \\
\hline Maximum phase voltage (Vmax) & $33 \mathrm{kV}$
\end{tabular}

Fig 2 (a) show the published results from $[18,19]$. The published results are simulated by ATP program (blue line) and mathematically analysed (red points). As a confidence test for ATP, a comparison between the published results and ATP simulation results.

By comparing the published results with the simulated one, the results are found to be close. Referring to Fig 2 (b), the TRV is increased to the maximum phase voltage from $33 \mathrm{kV}$ (red line) to $40.5 \mathrm{kV}$ with rise time ( $\left.\mathrm{T}_{\mathrm{r}}\right)$ equals $29.5 \mu \mathrm{s}$ (blue line).

\section{B. Effect of Single Power System Parameter on TRV}

As mentioned before, the nature of the circuit being interrupted affects the TRV waveshape. Therefore, the effect of using various parameters for the damping RC branch is studied.

The damping RC branch is added in parallel with the circuit breaker because of the higher RRRV of the TRV since the tested power system has inductive characteristics.

The effect of using different values of the resistance $\left(R_{p}\right)$ or the capacitance $\left(C_{p}\right)$ is evaluated. The values of the other system components such as network impedance are kept constant.

For the first case, three different values of $R_{p}$ are represented. At the beginning, $R_{p}$ is $200 \Omega$, then the value of $R_{p}$ is changed to $100 \Omega$. Finally, the value of $R_{p}$ is changed to 2000 $\Omega$. Fig. 3 (a) shows The TRV appears at the circuit breaker contacts for the three different values of $R_{p}$.

The results show that, for $R_{p}=200 \Omega$, the maximum TRV is $40.5 \mathrm{kV}$ with $\mathrm{T}_{\mathrm{r}}$ equals to $29.5 \mu \mathrm{s}$. However, for $\mathrm{R}_{\mathrm{p}}=100 \Omega$, TRV reaches $40 \mathrm{kV}$ with $\mathrm{T}_{\mathrm{r}}$ equals to $64.45 \mu \mathrm{s}$. For $\mathrm{R}_{\mathrm{p}}=2000$ $\Omega$, the maximum TRV is $33 \mathrm{kV}$ with $\mathrm{T}_{\mathrm{r}}$ equals to $4.6 \mu \mathrm{s}$.

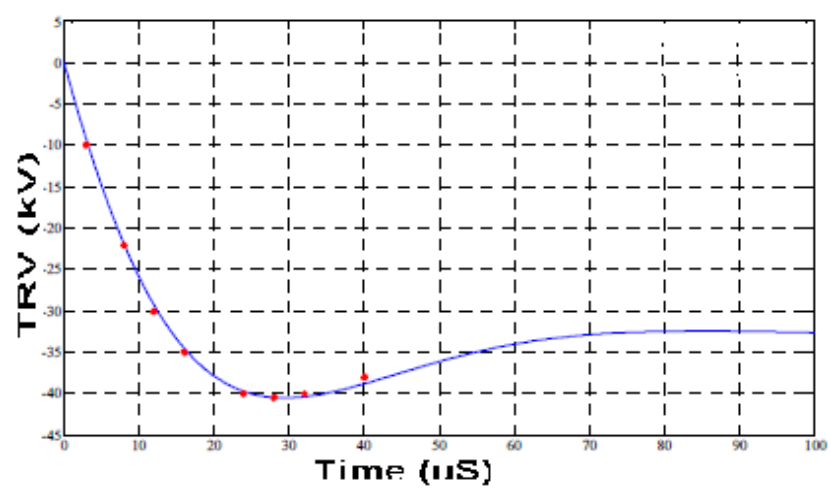

(a) Published

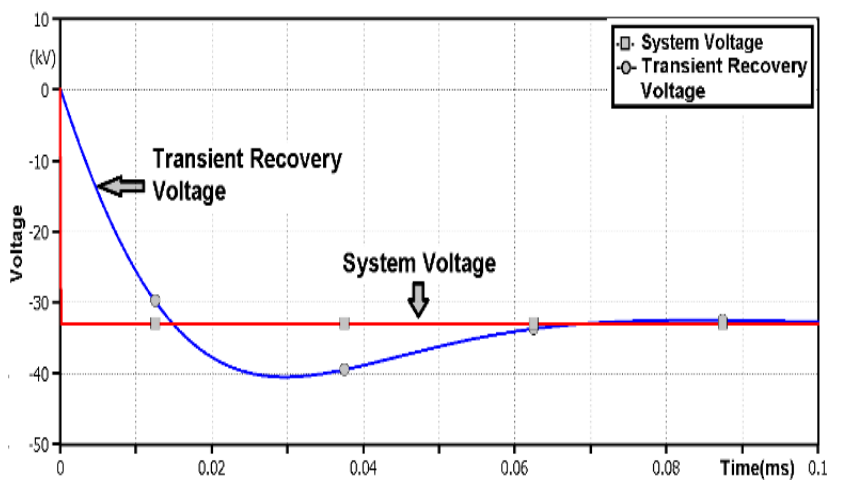

(b) Simulated

Fig. 2: The TRV Appears at the Circuit Breaker Contacts After Current Interruption.

It can be seen that the increasing of the resistance of the damping RC branch reduces the TRV amplitude and its rise time. For the highest tested value of $R_{p}\left(R_{p}=2000 \Omega\right)$ the TRV reduces to reach values close to its rated values.

For the second case, three different values of $C_{p}$ of the damping $\mathrm{RC}$ branch are represented. At the beginning, $\mathrm{C}_{\mathrm{p}}$ equals $85 \mathrm{nF}$, then the value of $\mathrm{C}_{\mathrm{p}}$ changes to $85 \mathrm{pF}$, and finally, the value of $\mathrm{C}_{\mathrm{p}}$ is increased to $85 \mu \mathrm{F}$. Fig. $6(\mathrm{~b})$ shows the TRV appears at the circuit breaker contacts for the three different values of $C_{p}$ of the damping $R C$ branch.

The results show that, the maximum TRV is $63.64 \mathrm{kV}$ with $\mathrm{T}_{\mathrm{r}}$ equals to $1.3 \mu$ s for $\mathrm{C}_{\mathrm{p}}=85 \mathrm{pF}$ compared with $40.5 \mathrm{kV}$ with $\mathrm{T}_{\mathrm{r}}$ equals to $29.5 \mu \mathrm{s}$ for $\mathrm{C}_{\mathrm{p}}=85 \mathrm{nF}$. The most reduced value of TRV are $32.5 \mathrm{kV}$ with $\mathrm{T}_{\mathrm{r}}$ equals $42 \mu$ s for $\mathrm{C}_{\mathrm{p}}=85 \mu \mathrm{F}$.

From the results, when the capacitance of the damping RC branch increase the TRV amplitude is reduces, however the TRV rise time is still above the acceptable limits. For $C_{p}=85$ $\mu \mathrm{F}$, the highest test value, the TRV is reduced to reach value close to the rated voltage value.

On the contrary, the reduction of the capacitance of the damping RC branch increases the TRV amplitude and creates an oscillatory TRV waveshape. This can be attributed to the absence of any devices can causes damping, such as transformer or transmission line, in the tested system.

Table 2 summarized the effect of using different values of the resistance or the capacitance of the damping RC branch on TRV amplitude and rise time. 


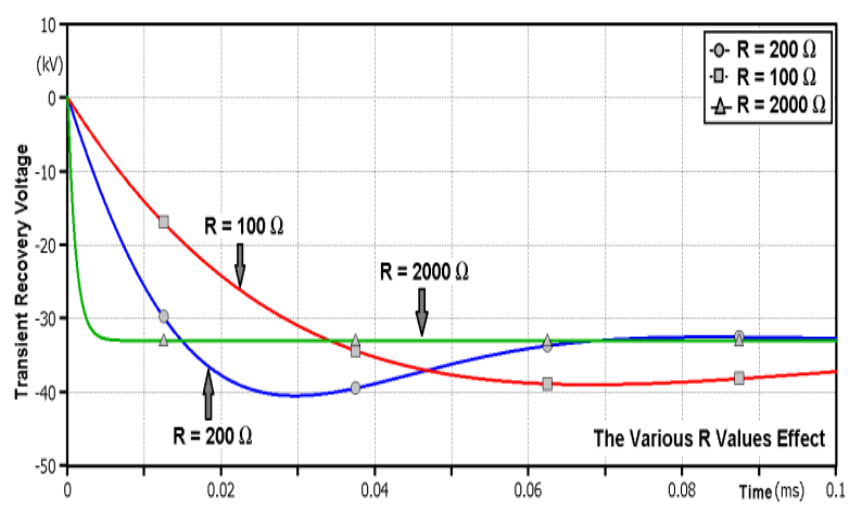

(a) The Resistance

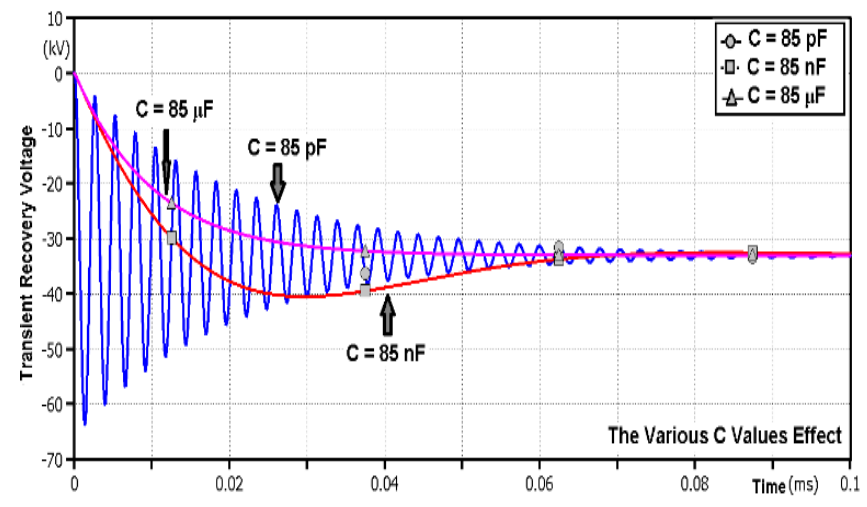

(b) The Capacitance

Fig. 3: The TRV at the Circuit Breaker Contacts for Different Values of the Damping RC Branch Parameters.

TABLE 2

The Effect of Using Different Values of the Resistance or the Capacitance of the Damping RC Branch on TRV.

\begin{tabular}{l||c||c||c} 
Component & Values & TRV $(\mathbf{k V})$ & Rise Time $(\boldsymbol{\mu s})$ \\
\hline \multirow{3}{*}{ Resistance } & $\mathrm{R}_{\mathrm{p}}=100 \Omega$ & 40 & 64.4 \\
\cline { 2 - 4 } & $\mathrm{R}_{\mathrm{p}}=200 \Omega$ & 40.5 & 29.5 \\
\cline { 2 - 4 } & $\mathrm{R}_{\mathrm{p}}=2000 \Omega$ & 33 & 4.6 \\
\hline \multirow{3}{*}{ Capacitance } & $\mathrm{C}_{\mathrm{p}}=85 \mathrm{pF}$ & 63.64 & 1.3 \\
\cline { 2 - 4 } & $\mathrm{C}_{\mathrm{p}}=85 \mathrm{nF}$ & 40.5 & 29.5 \\
\cline { 2 - 4 } & $\mathrm{C}_{\mathrm{p}}=85 \mu \mathrm{F}$ & 32.5 & 42
\end{tabular}

\section{Effect of Mixed Power System Parameters on TRV}

The magnitude of the TRV normally does not depend directly on any single parameter and a variation of one parameter can often alter the influence of another parameter. Therefore, studying the combination between the various system parameters is important.

The effect of using different values of the damping RC branch parameters, $R_{p}$ and $C_{p}$, is evaluated. The values of the other system component such as network impedance are kept constant.

Four different cases are studied, in this subsection, with two different values of each parameter.

For the first case, $R_{p}$ equals $100 \Omega$, and the value of $C_{p}$ is 85 $\mathrm{pF}$. This case is a combination of the smallest test values of these parameters, in this study.

At the second case, a combination of the highest test values of the damping RC branch parameters is discussed. Therefore, the value of $R_{p}$ is $2000 \Omega$, and $C_{p}$ equals $85 \mu \mathrm{F}$.

For the third case, the smallest test value of $R_{p}$ is combined with the highest test value of $C_{p}$, Therefore, the value of $R_{p}$ equals $100 \Omega$, and $C_{p}$ is $85 \mu \mathrm{F}$. Finally, a combination of the highest test value of $R p$ and the smallest test value of $C_{p}$ is studied. Therefore, at the fourth case, the value of $R_{p}$ equals $2000 \Omega$, and $\mathrm{C}_{\mathrm{p}}$ is $85 \mathrm{pF}$.

Fig. 4 shows the effect of using different values of the damping RC branch parameters on TRV which appears at the circuit breaker contacts.

Using a combination of the smallest tested values of $R_{p}$ and $\mathrm{C}_{\mathrm{p}}$, for the first case increases the TRV amplitude with transient behaviour and sawtooth TRV waveshape.

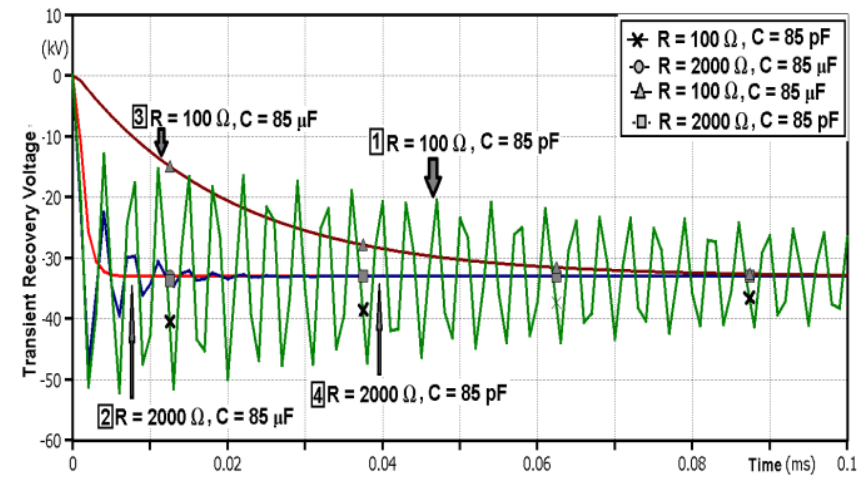

Fig. 4: The Effect of Using Different Values of the Damping RC Branch Parameters on TRV Appears at the Circuit Breaker Contacts.

However, at the second case, with the combination of the highest test values of the damping RC branch parameters, both of the TRV amplitude and TRV rise time are reduced.

For the third case, using the smallest test value of $R_{p}$ with the highest test value of $C_{p}$ results in a reduction of the TRV amplitude; however their rise time is not reduced.

Finally, for the fourth case, the combination of the highest tested value of $R_{p}$ and the smallest tested value of $C_{p}$ results in a reduction of the TRV amplitude but it takes time to reach the rated voltage values due to the existence of initial TRV.

The first case and the third case do not live up to the required results. Because one of the TRV main characteristics, the TRV amplitude or the TRV rise time, are not reduced in both cases.

The second case and the third case concluded that using the highest test value of $R_{p}$ results in the reduction of the TRV amplitude. And using the highest test value of $\mathrm{C}_{\mathrm{p}}$ results in the reduction of the TRV rising time.

So, the combination of the highest tested values of the damping RC branch parameters, at the second case, is the best case scenario. Table 3 summarized the effect of using different values of the damping $\mathrm{RC}$ branch parameters on the TRV. TABLE 3

The Effect of Using Different Values of the Damping RC Branch Parameters

\begin{tabular}{c||c||c||c||c} 
Case & $\begin{array}{c}\text { Resistance } \\
\text { Values }\end{array}$ & $\begin{array}{c}\text { Capacitance } \\
\text { Values }\end{array}$ & $\begin{array}{c}\text { TRV } \\
(\mathbf{k V})\end{array}$ & $\begin{array}{c}\text { Rise Time } \\
(\boldsymbol{\mu s})\end{array}$ \\
\hline First & $\mathrm{R}_{\mathrm{p}}=100 \Omega$ & $\mathrm{C}_{\mathrm{p}}=85 \mathrm{pF}$ & 52.12 & 2 \\
\hline Second & $\mathrm{R}_{\mathrm{p}}=2000 \Omega$ & $\mathrm{C}_{\mathrm{p}}=85 \mu \mathrm{F}$ & 33 & 9 \\
\hline Third & $\mathrm{R}_{\mathrm{p}}=100 \Omega$ & $\mathrm{C}_{\mathrm{p}}=85 \mu \mathrm{F}$ & 32.8 & 99 \\
\hline Fourth & $\mathrm{R}_{\mathrm{p}}=2000 \Omega$ & $\mathrm{C}_{\mathrm{p}}=85 \mathrm{pF}$ & 33.02 & 34
\end{tabular}

\section{Mitigation OF TRV USING SUPERCAPACITOR}

In this section, the effect of using supercapacitor as TRV 
mitigation method is studied. Changing the resistance and the capacitance of the simple power system is found to be effective on TRV mitigation. Replacing the damping branch capacitance with a superapacitor looks like a step worth studying.

Taking the advantage of the supercapacitor installation at power systems and using it as a transient mitigation method is a new trend in transient analysis studies [20].

\section{A.Modeling of Supercapacitor-Based Mitigation Method}

There are many models and equivalent circuits introduced in the literatures for supercapacitor. The parameters of the supercapacitor-based mitigation method include capacitance (C), equivalent series resistance $\left(\mathrm{R}_{\mathrm{S}}\right)$, and equivalent parallel resistance $\left(\mathrm{R}_{\mathrm{m}}\right)[21,22]$.

The equivalent series resistance $\left(R_{S}\right)$ is usually describes internal resistance of the supercapacitor. $R_{S}$ is almost in the range of 100 milliohms to $10 \mathrm{ohms}$ but influences the energy efficiency and power density [7, 23].

The equivalent series resistance (RS) for the proposed supercapacitor-based mitigation method is given by:

$R_{S}=V_{C}^{2} /(4 \times P \max )$

where $\mathrm{P}_{\max }$ is the maximum dischargeable power, and $\mathrm{V}_{\mathrm{c}}$ is the average voltage across the capacitor [23].

The capacitance $\mathrm{C}$ of the supercapacitor-based mitigation method can be expressed by:

$C=(2 \times E) / V_{S C}{ }^{2}$

where $V_{\text {SC }}$ is the supercapacitor rated voltage, and $E$ energy storage capacity.

The equivalent parallel resistance $\left(R_{m}\right)$ is in the range of several kilo-ohms and decides the leakage current when the supercapacitor is in a standby mode [22, 23]. The parameters of the supercapacitor-based mitigation method model are given in Table 4.

\section{B. The Supercapacitor-Based Mitigation Method Effect on TRV at Single Phase System}

The effectiveness of the supercapacitor as TRV mitigation method is studied. The switching operations are applied at $\mathrm{t}=0.0001 \mathrm{~s}$. The parameters of the test power system are given in Table 1. The supercapacitor replaced $C_{p}$ in the damping $R C$ branch. Meanwhile, $\mathrm{R}_{\mathrm{P}}$ is replaced by a damping resistance equals $2000 \Omega$.

The tested power system after adding the supercapacitor and the damping resistance are illustrated in Fig. 5

Fig. 6 shows the effect of using the supercapacitor with and without damping resistance on TRV appears at the circuit breaker contacts.

Due to the switching operation, the TRV is increase to 40.5 $\mathrm{kV}$ with $\mathrm{T}_{\mathrm{r}}$ equals $29.5 \mu$ s from its steady state voltage. Using the supercapacitor without damping resistance, the maximum TRV is decreased to the steady state values with $T_{r}$ equals 63 $\mu \mathrm{s}$. By adding the damping resistance to the supercapacitor, the maximum TRV is decreased to the steady state values with $\mathrm{T}_{\mathrm{r}}$ equals $6 \mu \mathrm{s}$.

From the simulation results, it is shown that the supercapacitor has a good effect with the damping resistor for the TRV mitigation.

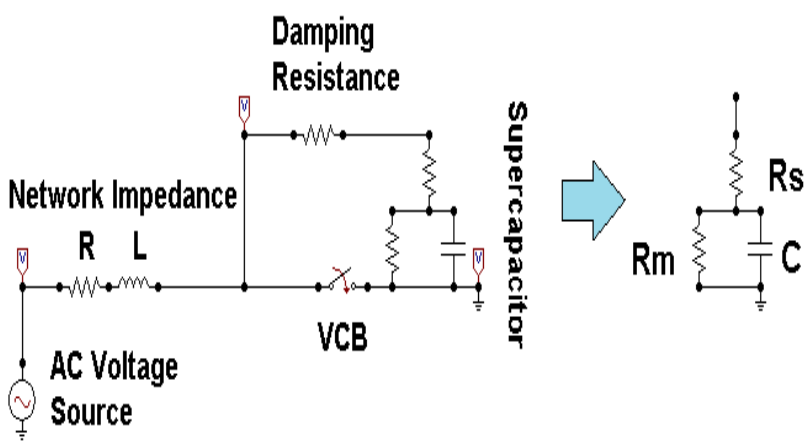

Fig. 5: The ATP Model of the Test Power System with the Supercapacitor and the Damping Resistance.

TABLE 4

The Proposed Supercapacitor -Based Mitigation Method Model DATA

\begin{tabular}{c||c||c||c||c||c} 
Parameter & Value & Parameter & Value & Parameter & Value \\
\hline $\mathrm{R}_{\mathrm{S}}$ & $0.35 \Omega$ & $\mathrm{C}$ & $22 \mathrm{mF}$ & $\mathrm{R}_{\mathrm{P}}$ & $2 \mathrm{k} \Omega$
\end{tabular}

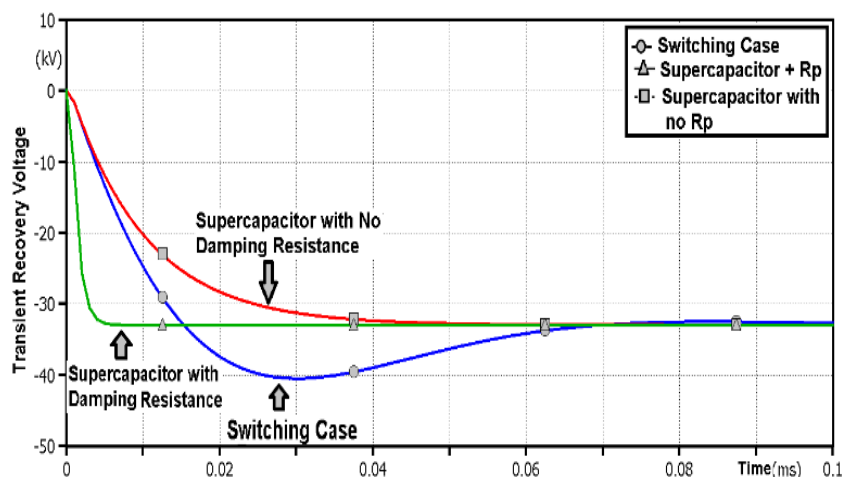

Fig. 6: The Effect of using the Supercapacitor with and without Damping Resistance on TRV.

\section{CONCLUSION}

In this paper, the TRV is mitigated using a supercapacitorbase mitigation method in a simple power system. The TRV concept and the phenomena surround its occurrence such as reignition and restrike are represented. Also, the different waveshapes of TRV are evaluated. The effect of various power system parameters on TRV at the tested power system is investigated using ATP/EMTP.

From the simulation results, it can be concluded that the increasing of the resistive component in the test system reduces the TRV characteristics to ideal values. However, increasing the capacitive component in the test system reduces the TRV values; however their rise time is not reduced.

A Combination of the highest values of the resistive and capacitive components in the test system results in the reduction of the TRV. However, the increasing of the capacitance value is an issue.

Therefore, a supercapacitor-based mitigation method is proposed and tested. The results show that the supercapacitor has a good effect with the damping resistor for the TRV mitigation. 


\section{REFERENCES}

[1] H. Yang, "Analysis of Supercapacitor Charge Redistribution Through Constant Power Experiments", 2017 IEEE Power \& Energy Society General Meeting, Chicago, USA, July 16-20, 2017.

[2] M. Farhadi and O. Mohammed, "Energy storage technologies for high-power applications", IEEE Transactions on Industry Applications, Vol. 52, No. 3, 2016 pp. 1953-1961.

[3] V. I. Herrera, H. Gaztanaga, A. Milo, A. S. de Ibarra, I. Otadui, and T. Nieva, "Optimal energy management and sizing of a batterysupercapacitor-based light rail vehicle with a multiobjective approach," IEEE Transactions on Industry Applications, 2016, Vol. 52, No. 4, pp. 3367-3377.

[4] R. Rifaat, T. Singh Lally and J. Hong, "Circuit Breaker Transient Recovery Voltage Requirements for Medium Voltage Systems with NRG", IEEE Transactions on Industry Applications, 2014, Vol.50, No. 5, pp. $2989-2995$.

[5] IEEE Std. C37.011-2011,"IEEE Approved Draft Guide for the Application of Transient Recovery Voltage for AC High-Voltage Circuit Breakers with Rated Maximum Voltage above 1000V", IEEE PC37.011/D9, September 2018.

[6] J. C. Das," Analysis and Control of Large Shunt Capacitor Bank Switching Transients", IEEE Transactions on Industry Applications, 2005, Vol. 41, No. 6, pp. $1444-1451$.

[7] M. Belkhayat, J. Edwards, N. Hoonchareon, O. Marte and D. Stenberg, "Transients in Power Systems", ECE Technical Reports, Electrical and Computer Engineering, 1995, Paper No. 168, available at: http://docs.lib.purdue.edu/ecetr/168.

[8] M. McGranaghan, R. Zavadil, G. Hensley, T. Singh, and M. Samotyj, "Impact of Utility Switched Capacitors on Customer Systems Magnification at Low Voltage Capacitors", IEEE Transactions on Power Delivery, Vol. 7, No. 2, April 1992, pp. 862868.

[9] D. Nobre ,W. Neves, and B. de Souza, "An Alternative to Reduce Medium-Voltage Transient Recovery Voltage Peaks", International Conference on Power Systems Transients, IPST 2001, Rio de Janeiro, Brazil, June 24-28, 2001, Paper No: 136.

[10] D. Swindler, P. Schwartz, P. Hamer and S. Lambert, "Transient Recovery Voltage Considerations in the Application of MediumVoltage Circuit Breakers", IEEE Transactions on Industry Applications, Vol. 33, No. 2, March/April 1997, pp. 383-388.

[11] H. Bahirat, M. Ali and K. Praveen, "Effects of Transient Recovery Voltages on Circuit Breaker Ratings", Power System Transients, Spring 2008.

[12] R. Alexander and D. Dufournet,"Transient Recovery Voltage (TRV) for High-Voltage Circuit Breakers", IEEE Tutorial, Calgary, Canada, October 2008.

[13] S. Chandankar and A. A.Bhole, "Review: to Investigate Impacts of Various Factors on the Characteristics of Transient Recovery Voltage", International Journal of Advanced Research in Electrical, Electronics and Instrumentation Engineering, IJAREEIE, Vol. 5, No. 12, December 2016, pp. 8821-8825.

[14] H. A Halim, N. S. Noorpi, N. M. Mukhtar and M. Amirruddin, "Simulation Study of the Transient Recovery Voltage (TRV) on Circuit Breaker", $5^{\text {th }}$ International Conference on Computational Intelligence, Modeling and Simulation, Seoul, South Korea, Sep. 24-26, 2013.

[15] W. E. Reid, "Effect of Transient Recovery Voltage (TRV) on Power System Interruption", Report Power Systems, 1987.

[16] B. Filipovi, I. Ugleši and D. Filipovi, "Analysis of Transient Recovery Voltage in $400 \mathrm{kV}$ SF6 Circuit Breaker Due to Transmission Line Faults", International Review of Electrical Engineering, IREE, Vol. 6, No. 5, Sept.-Oct. 2011, pp. 2652-2658.
[17] N. Kafshgari, N.Ramezani, and H. Nourib, "Effects of High Frequency Modeling \& Grounding System Parameters on Transient Recovery Voltage Across Vacuum Circuit Breakers for Capacitor Switching in Wind Power Plants", International Journal of Electrical Power \& Energy Systems, Vol. 104, Jan. 2019, pp. 159-168.

[18] A. Soloot, A. Gholami, and K. Niayesh, "Study on Post Arc Current and Transient Recovery Voltage in Vacuum Circuit Breaker", International Review of Modeling and Simulations, IREMOS, Vol. 4, No. 2, April 2010.

[19] A. Soloot, and H. Hoidalen,"Upon the Impact of Power System and Vacuum Circuit Breaker Parameters on Transient Recovery Voltage", Asia-Pacific Power and Energy Engineering Conference, Chengdu, China, March 28-31, 2010.

[20] Eman A. Awad , Ebrahim A. Badran and Fathi H. Youssef," Mitigation of Switching Overvoltages in Microgrids Based on SVC and Supercapacitor", IET Generation, Transmission \& Distribution Journal, Vol. 12, No. 2, Jan. 2018, pp. 355-362.

[21] R. Spyker, and R. Nelms, "Classical Equivalent Circuit Parameters for a Double-Layer Capacitor", IEEE Transactions on Aerospace and Electronic Systems, Vol. 30, No. 3, July 2000, pp. 829-836.

[22] A. Hajizadeh, M. Golkar, and L. Norum, "Robust Control of Hybrid Fuel Cell/Energy Storage Distributed Power Generation System in Weak Grid under Balanced and Unbalanced Voltage Sag", European Transactions on Electrical Power, Vol. 21, No.1, January 2011, pp. $522-540$.

[23] K. Sahay, and B. Dwivedi, "Design and Analysis of Supercapacitor Energy Storage System for Energy Stabilization of Distribution Network", Electrical Power Quality and Utilisation, Vol. 15, No.1, 2009, pp. 25-32.

[24] S. James, N. Kularatna, A. Ross, and R. Kunnemeyer, "Estimation of Transient Surgy Energy Transferred with Associated Time Delays for Individual Components of Surge Protector Circuits", Institution of Engineering and Technology, IET Power Electronics Journal, Vol. 8, No.5, 2015, pp. 685-692.

\section{Title Arabic:}

اخماد جهود الاسترداد العابرة باستخدام المكثف الفائق

\section{Arabic Abstract:}

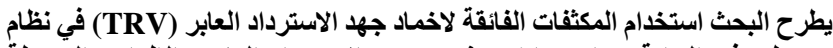

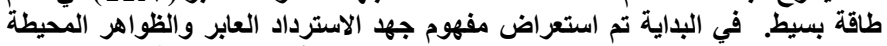

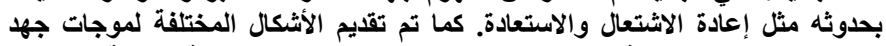

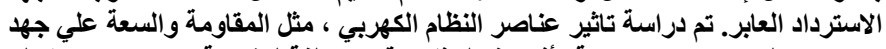

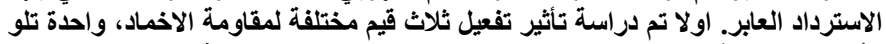

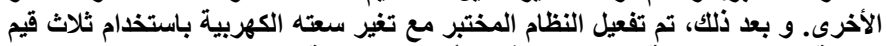

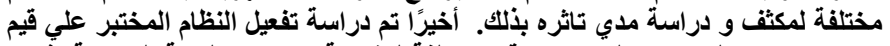

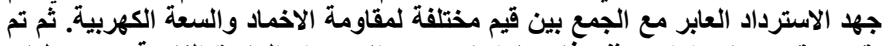

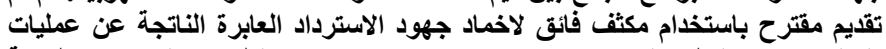

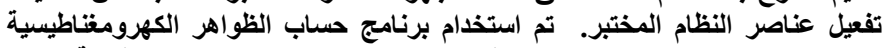

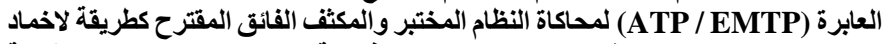

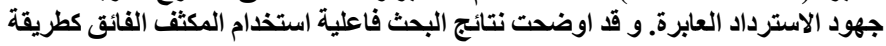
لاخماد جهود الاسترداد العابرة. 